\title{
HYDRODIPLOMACY IN PRACTICE: TRANSBOUNDARY WATER MANAGEMENT IN NORTHERN GREECE
}

\author{
Y. MYLOPOULOS* \\ E. KOLOKYTHA \\ D. VAGIONA \\ E. KAMPRAGOU \\ E. ELEFTHERIADOU
}

Received: 08/01/07

Accepted: 02/04/07

\author{
${ }^{1}$ Aristotle University of Thessaloniki \\ Department of Civil Engineering \\ Division of Hydraulics and Environmental Engineering \\ Thessaloniki, 541 24, Greece
}

\begin{abstract}
The political dimension of water becomes highly important not only because of its scarcity, but also as a result of its sharing across national boundaries. Approximately $40 \%$ of the global population lives in tranboundary water basins, emphasizing the need for cooperation and harmonization of policies. Hence, the need for "Hydrodiplomacy" rose under the framework of sustainable development and international cooperation.

Especially in Greece, management of transboundary rivers is of major importance, since roughly $25 \%$ of the country's renewable resources are "imported" as in four out of the total five transboundary rivers Greece is the downstream country. The lack of transboundary water agreements between Greece and its neighboring countries (except with Bulgaria) is affecting greatly the international cooperation and the status of the water resources. Hence, the implementation of appropriate methodologies is crucial for the promotion of the integrated management of these areas. This study refers to five transboundary basins in Northern Greece and introduces the principles of "Hydrodiplomacy" in their management.
\end{abstract}

KEYWORDS: water management, international co-operation, transboundary rivers and lakes, European projects

\section{INTRODUCTION}

The political dimension of water becomes highly important not only because of its scarcity, but also as a result of its sharing across national boundaries. Approximately $40 \%$ of the global population lives in tranboundary water basins, shared by more than one country, emphasizing the need for concerted management of transboundary water bodies and harmonization of policies. Under this view, water should be managed in an internationalized way, integrating methodologies and techniques mainly used in the sciences of international relations and diplomacy.

The principles of sustainable development introduced the need for the innovative "Green" or "Environmental" Diplomacy, which aims at strengthening international co-operation for environmental protection under the framework of good neighboring and management of common goods. In the water sector, this new diplomatic approach is known as "Hydrodiplomacy" and its main principles are: effectiveness, efficiency, equality, equivalence and equity (Vlachos, 1999).

Management of transboundary rivers is a major issue for Greece as the majority of North Greece's rivers originate in neighbour countries. In addition to this fact, Greece is the downstream country in four out of the five shared rivers and roughly $25 \%$ of the country's renewable resources are "imported". Inevitably, the applied management policy of the upstream countries affects directly every economic activity, as well as the protection of important ecosystems in N. Greece. Since Greece is a full member of the European Union 
$(E U)$, the European Guidelines provide the platform in which Hydrodiplomacy can be based on. In relation to water management, the Water Framework Directive 2000/60 introduces river basin management and integrated water management, not only for the EU members but also for the candidate countries, providing thus a common framework for the co-operation, planning and management of water resources (EU, 2000).

\section{EUROPEAN PROJECTS ADDRESSING TRANSBOUNDARY WATER MANAGEMENT}

European Union places a great importance on integrated water management and transboundary co-operation by creating legislative tools, like the Water Framework Directive 2000/60, and promoting Hydro-diplomacy in order to harmonize the methodologies and enhance co-operation. A number of research projects have been funded in this direction. Aristotle University of Thessaloniki has participated in three projects concerning transboundary water basins of Greece: IRON CURTAIN, TRANSCAT and TRABOREMA.

The «IRON CURTAIN» project belongs to the Fifth Framework Programme (part «Quality of Life and Management of Living Resources»), in which universities, research institutes and agencies from 8 countries participated (Norway, Russia, Germany, Czech, Austria, Hungary, Greece, Bulgaria). The goal of the project was to develop a methodology leading to standardized tools and procedures for integrated resource evaluation, analysis and management following the principles of sustainable development. The developed methodology was tested and scaled in six case studies along a European north/south traverse, with Nestos basin being the southern pilot area. For Nestos basin the focus was set on the integration of water management, agricultural activity and environmental protection.

Another research project under the Fifth Framework Programme is TRANSCAT: "Management of Transboundary Catchments" (Key Action "Sustainable Management and Quality of Water") aiming to create an operational and integrated comprehensive Decision Support System (DSS) for optimal water management in borderland regions in context of the implementation of the EU Water Framework Directive. The developed multi-lingual DSS will comprise an innovative tool for the management of transboundary catchments, incorporating environmental, socio-economic and cross-border issues. Nine European countries participated in the project and five pilot sites have been selected in order to provide a good contrast in transboundary area typology (TRANSCAT Compendiym, 2006). River Nestos was chosen as the Greek reference area where the DSS is primarily focused on water quantities issues and socio-economic models.

The TRABOREMA project is focused on stabilizing and reinforcing research potential in the field of integrated management, regional water resources planning and policy in a transboundary lake region between Albania, FYROM and Greece. Using the EU Water Framework Directive as a guideline, a common monitoring system in the catchment of Lake Prespa will be designed and implemented. Upstream/downstream water demands are being analyzed in order to determine environmental pressures and impacts in terms of ecological quality ratios (EQR) for the target region. The results will be used as a basis for transboundary policy recommendation aiming at integrated management of water resources and sustainable socioeconomic development of the region.

\section{CASE STUDIES IN NORTHERN GREECE}

In N. Greece there are five tranboundary rivers, four originate from FYROM and Bulgaria (Axios, Strymonas, Nestos, Evros) while the fifth one (Aoos River) flows from Greece into Albania and two transboundary lakes: Prespa and Doirani lake.

\section{Nestos river}

The catchment of the river Nestos/Mesta is sited at the SW corner of Bulgaria and at the area of E. Macedonia and W. Thrace in Greece. Approximately $60 \%$ of the basin area belongs to Bulgaria while the rest to Greece. Having in mind the high-mountain and virgin character of the upper reaches of Nestos river (almost unaffected) its water represents a resource of exceptional significance, both on local, national and transboundary level. Although a provisional inter-government agreement for the use of the Nestos water was signed between 
Bulgaria and Greece, the lack of a clear mutually based concept for regional development may create potential conflicts in the future.

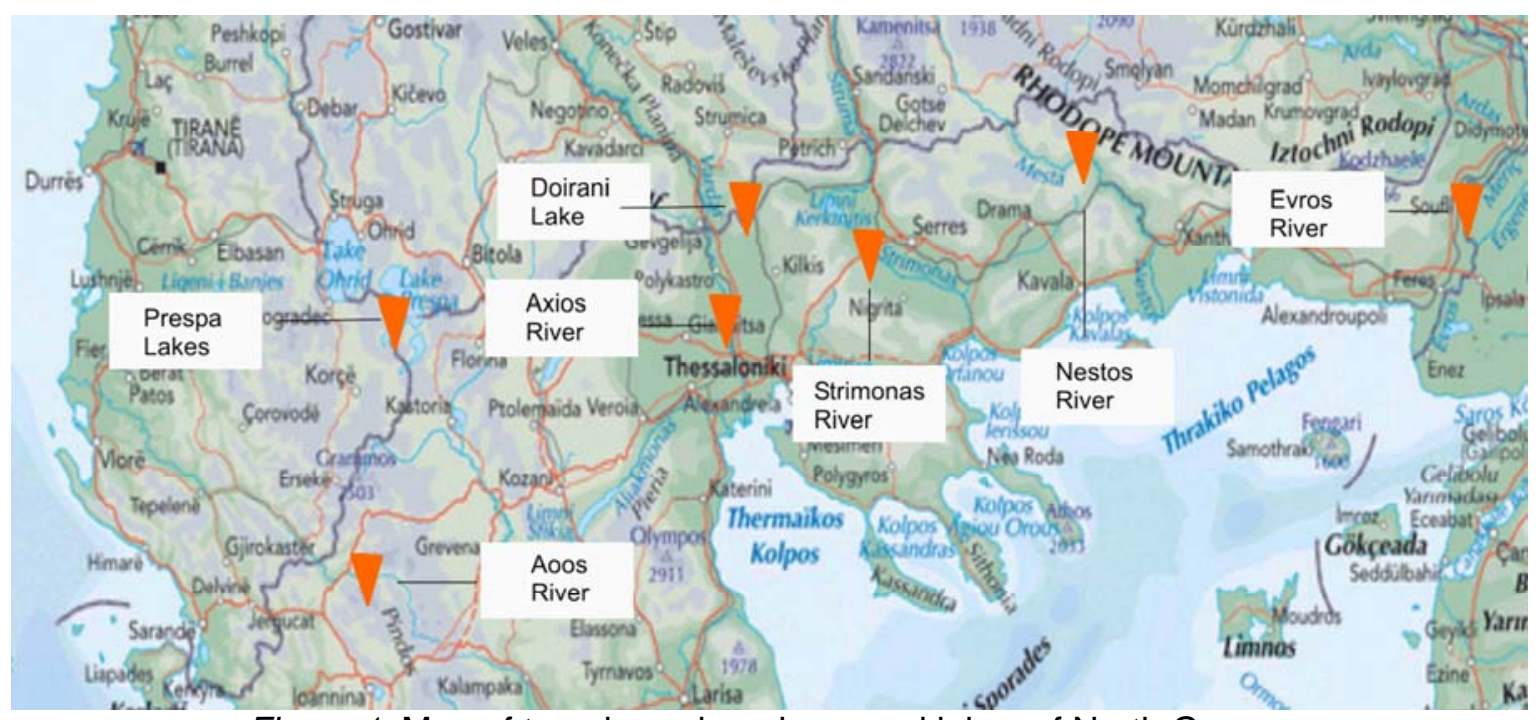

Figure 1. Map of transboundary rivers and lakes of North Greece

(source of map: www.multimap.com)

The negotiations between the two countries have started on 1964 with dominant issue the allocation of the river flow. The two parties through a bargain-game concluded to the $29 \%$ of the total volume that is generated in the Bulgarian territories to be entering Greece (Greek National Legislation, 1996). According to the agreement, both parties are bound to exchange information concerning the water status and any development plans that would affect the natural flow of the river. International conventions, standards and European guidance are also applicable for the improvement of water quality and the conservation of the ecosystem. Moreover, a cross-border Commission of Hydroeconomy will be established, responsible for the observation and control of the application of the agreement. The commission will also be the intermediary factor for any possible disputes and in case of failure the matter will be forwarded to a governmental level. The agreement was signed in $22^{\text {nd }}$ of December 1995 and since then both countries failed to show a joint effort to put it into action.

The agreement has received a lot of criticism, since it is characterized by generalities (Mylopoulos et al., 2004). The agreed allocation scheme seems a result of political bargaining rather than aiming at meeting the requirements of the local population. For this reason, the agreement has not received the necessary public support so far. The co-operation of the two countries is problematic in relation to information exchange and so it fails to set the background conditions for future development of a common water management plan. No special attention was given to water quality issues or alternative allocation scenarios in cases of extreme phenomena.

In conclusion, although the agreement contains some principles set by international organizations, like the EU (e.g. Water Framework Directive 2000/60) or the United Nations (e.g. Helsinki Rules), such as willingness for co-operation, exchange of data and creation of cross-border commission, it still remains inactive. In order for the agreement to be compatible with international requirements, three steps are necessary. Firstly, the development of a joint river basin management plan, secondly the specification of the term $29 \%$ of water flow and thirdly the creation of a common management body, which will include also representatives from local authorities. If there is a common willingness to cooperate, then with some necessary alterations the two countries can reach the compliance with EU directives and the UN conventions, developing an integrated policy, which will be beneficial for both countries and mostly for the local population. 


\section{Prespa lakes}

The Prespa Lakes are shared among Albania, Greece and FYROM. The total Prespa area, combining the drainage basins, and the lakes, is $2,519.1 \mathrm{~km}^{2}$ and is part of the Lake Ohrid Watershed. Of the total water mirror surface, $190 \mathrm{~km}^{2}$ belong to FYROM, $84.8 \mathrm{~km}^{2}$ to Greece and $38.8 \mathrm{~km}^{2}$ to Albania. The Micro Prespa Lake is shared only between Greece and Albania.

The Macro and Micro Prespa lakes and their catchment basin are regulated and protected under a series of National, Community and International legal instruments. In Albania and Greece, almost the whole Prespa catchment is covered by a single protected area in the form of National Park (or National Forest in the case of Greece). In FYROM, the Prespa catchment is much larger and includes at least three separate protected areas (Galicica National Park, Pelister National Park and Ezerani National Reserve). All these areas are characterized by high habitat diversity, with rich flora and fauna.

Although there are adequate laws supporting water resources management in all three countries, there are difficulties concerning data exchange and information flow both on a national and transboundary level. Furthermore, there is a failure to implement basic laws concerning both water resources management and the protection and restoration of the environment.

There are many Ministries, institutions and organizations both governmental and nongovernmental involved in water resources management. Each of them has its own goals and objectives and concentrates specifically on one or more aspects of water resources management, ignoring in the process some other fundamental issues. What is missing in each of the three countries is a unified self-existent body for the management of national water resources.

As a full member of European Union, Greece has an obligation to comply with the EU Water Framework Directive, and as possible future candidate countries Albania and FYROM should consider adapting the main principles of EU Water Framework Directive. It is up to each Member State to review the status and particularities of its water resources and develop its own national strategy. The WFD provides member States with an opportunity for introducing and implementing water policies that enhance the sustainability of water resources.

On the $2^{\text {nd }}$ of February 2000, on the occasion of World Wetlands Day, the Prime Ministers of the three countries met at Aghios Germanos in Greece and signed a declaration on the Creation of the Prespa Park and the Environmental Protection and Sustainable Development of the Prespa Lakes and their Surroundings. In the context of this declaration, joint actions would be considered in order to: a) maintain and protect the unique ecological values of the "Prespa Park", b) prevent and/or reverse the causes of its habitat degradation, c) explore appropriate management methods for the sustainable use of the Prespa Lakes water, and d) to spare no efforts so that the "Prespa Park" become and remain a model of its kind as well as an additional reference to the peaceful collaboration among the three countries.

As a follow -up to the Declaration of Prespa Park, the three states have established an interim "Co-ordination Committee for the Prespa Park" (PPCC) which includes representatives from the environmental authorities, local government, and NGO community in each country as well as the Ramsar Convention Bureau/MedWet as observer. The main responsibility of the Coordination Committee is to ensure coordination among the three countries and concerned stakeholders to facilitate the establishment of the trilateral Prespa Park, the protection of its ecosystems and the sustainable development of the region. The Committee is expected to become the formal body responsible for the implementation of the proposed transboundary, trilateral environmental and sustainable development program, benefiting the lake region.

\section{Axios river}

The Axios/Vardar River is located in the central Balkan Peninsula and originates from mountain Sar nearby the boundaries of FYROM and Albania discharging directly to Thermaikos Gulf. The river occupies a length of $380 \mathrm{~km}, 74 \mathrm{~km}$ of which are lying on the Greek territory. The Axios/Vardar basin combines a total area of $24.338 \mathrm{~km}^{2}$. Only $12.25 \%$ of the area belongs to Greece. The total population of the basin is approximately $1,960,000$ people. The Axios delta area is of great ecological value as it belongs to NATURA 2000 
network and is protected by Ramsar and Bern Conventions. Major problems are linked both with qualitative and quantitative aspects of water resources. Intensive human activities led to the destruction of almost $70 \%$ of the original wetland area. Untreated industrial waste disposal from FYROM and irrigation practices in the Greek part of the river contribute to water pollution

Two agreements have been signed before the partition of Yugoslavia, between Yugoslavia and Greece, concerning hydroeconomy issues and the improvement of the current situation in Axios/Vardar basin. These agreements have no validity at present, since a new country (FYROM) is now the second interested part. A new potential agreement should be focused on meeting the increased water demands mainly for agricultural purposes downstream, preserving the quality of the Thermaikos Gulf and maintaining the delta of the river.

Different socio-economic conditions and political tension between the two countries impede the establishment of an agreement. The intensive need for an agreement between FYROM and Greece can be justified by taking into account the following conditions:

- The integrity of the ecosystem of Axios basin, the agricultural areas of Kilkis and Thessaloniki plains, groundwater resources that are interrelated with the rivers'water and the quality of water in Thermaikos Gulf, where the river finally flows into, depend on the quality of water that enters from FYROM.

- In the city of Thessaloniki, the construction of a contemporary WWTP has recently been completed. Despite this, the risk of pollution still exists as a potential pollution accident from the upstream country could provoke significant pollution problems in the Gulf.

- Intensive agricultural activity in Axios valley exists, where the $77 \%$ of the total rice production of Greece is cultivated and almost the $85 \%$ of the mussel's production. Problems in water quantity and quality would end up to severe economic problems in the area.

Transboundary co-operation can be successfully established through joint management plans, joint river authorities and coordinated national measures. In the short term, bilateral cooperation could contribute to river protection and management. Common monitoring system in order to measure and control water quality and quantity parameters should be established with the participation of all interested parties while coordinating measures in a transboundary context should be adopted.

\section{Evros river}

Evros/Maritza/Meric river is the second biggest river in the Balkans after Danube river. It originates from Rila mountain in Bulgaria and after a distance of $530 \mathrm{~km}$ it discharges in the Aegean sea. The $218 \mathrm{~km}$ are the natural boundary between Greece- Bulgaria and GreeceTurkey respectively. It comprises a very important river system in the eastern part of Balkans with a total catchment area of $39.000 \mathrm{~km}^{2}, 66 \%$ of which belongs to Bulgaria, $28 \%$ to Turkey and only $6 \%$ to Greece. The estuary of the river, protected by Ramsar Convention, is well known for its rare ecosystem.

The construction of dams on the Bulgarian territory causes problems to both Turkey and Greece concerning the quantity of water that ends up on the downstream part of the basin. Moreover, new tensions are expected to raise, due to low groundwater levels in the region and seawater intrusion in the coastline. The maintenance of the Delta of the river, which has been characterized as one of the most important wetlands and environmental habitats in the world, remains another big challenge in the area.

Flood events in the Greek part of the river basin provoke severe problems to the regional economy. Even though certain flood prevention constructions exist in the Greek part, they are not able to prevent the problems effectively. Incentives for Bulgaria to construct the necessary hydraulic works in their territory that would prevent floods on the downstream part should be created in order to face the flooding risks.

Since Bulgaria is in a transition period concerning its development, and its accession in EU in 2007, it should reach such a level of development that it should be able to integrate successfully within the EU countries. For Evros/Meritsa river catchment this means to create the required premises for integral transboundary development of the entire catchment. Funds 
of the European Commission can be used for construction of water infrastructure within the existing common mechanisms. The related countries should take advantage of these opportunities in the field of the transboundary management. The support of Greece is critical in order to provide subsidies. Effective co-operation through the establishment of a transboundary agreement among the countries would be a way to solve these kinds of problems to the benefit of all. Poor level of co-operation concerning environmental problems and political tension between Greece and Turkey is also an impediment for the establishment of a potential agreement.

Past efforts concerning transboundary co-operation concern mainly Greece and Bulgaria dating back from 1964 (legal document 4393/1964). There are also other agreements in force, between Greece and Turkey concerning the control of hydraulic works on both banks of the river Maritza-Evros. The Agreement was signed in Ankara in 1934 and amended by a protocol in 1963.

\section{The Strymonas case}

The Strymonas/Struma river, with a total length of $400 \mathrm{~km}$ and a watershed of $18,078 \mathrm{~km}^{2}$, is shared between Greece, Bulgaria, FYROM and Serbia. The river flows from Vitosha mountain in the western part of Bulgaria $(290 \mathrm{~km})$ and ends up after a distance of $110 \mathrm{~km}$ in the Greek territory in the Aegean sea. The total population of the river basin is approximately 630,000 people. Irrigation needs and urban water demand are mainly covered by the river. Although there is no heavy industry in Bulgaria, water quality problems exist due to the lack of WWTPs and the irrigation practices on the upstream part of the river basin. Illegal hunting, fishery and water quality problems pose pressure in the ecosystem on the downstream part as well as in Kerkini lake. The only transboundary co-operation efforts concern a protocol between Geek Bulgarian experts for flood control signed in 1980 and the preparation of a common proposal in EU for a joint monitoring system for the measurement of quantity and quality parameters of the river made in 1991. The main drawback $n$ the area is that no transboundary agreement exists until now. The absence of an integrated management plan for the total river basin and of a joint water body may raise significant problems in the near future concerning the environmental protection of the river.

\section{The Doirani lake case}

Lake Doirani is located at the borders with FYROM. The catchment area of the lake is 270 $\mathrm{km}^{2}$, comprising also lake surface, of which $29.6 \%$ belong to FYROM and the rest to Greece. The water level of the lake is continually dropping (except during winter). The average annual fall of the level is $0.42 \mathrm{~m}$. During a 9-year period (1985-1993) the fall of water level in the lake has reached $3.84 \mathrm{~m}$.

The lake is characterized by a wide biodiversity, however fish production has dropped by one fifth in the past decade and bird population has also decreased. Major issues related to the preservation of the lake are the drilling for water on both sides of the border, intensive farming methods, and pollution from sewage. It is indicative that in the lake moderate oxygen depletion is observed (Skoulidikis et al., 1998).

The Greek Biotope/Wetland Center (EKBY) undertook a project in the framework of the Development Assistance Committee (DAC), a body operating within the framework of the Organisation for Economic Co-operation and Development (OECD). The aims of the project are: a) the identification of restoration measures for the transboundary Lake Doirani, b) the strengthening of bilateral cooperation (between Greece and FYROM) for the conservation and management of the lake (EKBY, 2003-2005)

The co-operation between Greece and FYROM mainly concerns policies on fishing in bordering internal waters and ad hoc meetings of fishery experts for defining a common annual quota, aiming at the protection of fish reproduction. Meetings of this kind take place in Doirani Lake, since 1996. FYROM has submitted a draft Protocol of Co-operation between the two countries on fishery issues, which has not yet been signed.

The present state of Lake Doirani shows the need for urgent measures to accomplish its efficient restoration and protection. Management of the lake's water and ecosystem cannot be 
considered separately from the water management of the whole catchment area, emphasizing the need for international cooperation and action.

\section{CONCLUSIONS}

Transboundary water resources of North Greece constitute a major asset for the country and introduce high uncertainty for the country's imported water due to the lack of efficient transboundary agreements. The majority of the transboundary resources are shared with Bulgaria and the two countries have started negotiations since 1964. Especially for Evros and Strymonas rivers there is no certain protective status, just general provisions from general agreements. Only in the case of Nestos river the legal framework is available but the implementation has been proved inefficient. Water quality and quantity of these transboundary rivers is highly affected by their use in the upstream countries. Especially water quality issues and the generated transboundary pollution should be confronted as a prior issue followed by the manipulation of urgent water quantity issues as the experienced extreme flooding events. Although many efforts have been made and many bilateral memoranda of co-operation have been signed between the two countries, the process of applying common management plans has been retarded. Co-operation took mostly place through fragmented measures, ignorance of the local needs, giving emphasis on securing users rights rather than treating transboundary rivers as a unity, which should be jointly protected and managed. Concerning the other countries, namely FYROM and Turkey, political tension makes the establishment of a transboundary agreement a hard task.

The Water Framework Directive could act as a guideline for international co-operation as it promotes the management of transboundary watercourses among EU and non EU countries. It requires the establishment of common management plans at the river basin level whereas the bilateral agreements signed so far between Greece and its neighbor countries do not contain similar provisions and none of the joint body established so far has the competence to undertake this responsibility. The issue of common planning and management is of great importance in effective transboundary co-operation. Since almost all of the neighbor countries are in an era of transition, it is a great opportunity for Greece as an EU full member state to proceed to agreements for the benefit of all.

Past experiences indicate the need for a common will to resolve problems and especially political willingness for co-operation. There should be confidence between the parties and their co-operation should be based on the principles of good neighborliness and reciprocity. Moreover, flexibility of a transboundary agreement is vital as emerging problems will always occur and new approaches have to be adopted for the neglected or underestimated issues. Certainly, all the above cannot take place without the transfer of authority to joint bodies accountable for the implementation of treaties to the basins in question.

All the above emphasize the importance of the utilization of "Hydrodiplomacy" to transboundary water resources, which will lead to the integrated water resources management accepting the river basin approach as a co-operative mechanism. New methods that promote participation should be applied in the water management sector in order to promote conflict resolution and consensus building. Political will and public participation can convert the existence of shared water resources from a problematic issue to a strong motivation for transboundary co-operation.

\section{ACKNOWLEDGEMENT}

Miss Eleni Eleftheriadou is scholar of the State Scholarships Foundation of Greece.

\section{REFERENCES}

1. Directive 2000/60 of the European Parliament and of the Council of 23 October 2000, establishing a framework for Community action in the field of water policy. 
2. EKBY (Greek Biotope/Wetland Centre) (2003-2005), DAC Doiran: Evaluating the functions of Lake Doirani and promoting conservation measures (Greece and FYROM), Project funded by the Hellenic Ministry of Foreign Affairs - HELLENIC AID.

3. Greek National Legislation, Law 2402/1996: The Bilateral Agreement between Greece and Bulgaria for the waters of Nestos River.

4. Mylopoulos Y., Eleftheriadou E. and Kampragou E. (2004) The transboundary catchment of River Nestos and the bilateral agreement between Greece and Bulgaria, ECO-Geowater conference, GI for International River Basin Management, Budapest, 3-5 June

5. Skoulikidis N.T., Bertahas I., Koussouris T. (1998) The environmental state of freshwater resources in Greece (rivers and lakes), Environmental Geology, 36(1-2), 1-17.

6. TRANSCAT Compendium (2006), Supporting Decision Making in Transboundary Catchments, Project No EVK1-CT2002-00124 "Integrated Water Management of Transboundary Catchments".

7. Vlachos E. (1999), Practicing Hydrodiplomacy in the 21 st Century, Water Resources Update, 111, 76-82. 